\title{
HYPOXAEMIA AFTER FRACTURES
}

\author{
S. S. TAChaKra and S. SevitT, Birmingham, England
}

From the Birmingham Accident Hospital

Serial arterial blood-gas analyses showed a phase of primary hypoxaemia in thirty-two out of fifty fracture patients (64 per cent) without head, chest or abdominal injury. The incidence was greater in those with shaft fractures of the femur or tibia or both, than in those with fractured hips, and was related to the severity of injury and the nature of the accident. Most affected subjects were already hypoxaemic on admission to hospital: the arterial $\mathrm{PO}_{2}$ commonly fell to between 60 and 70 millimetres of mercury, and the episode generally lasted a few days. The hypoxaemia was generally subclinical but four patients developed mild clinical fat embolism. Early hypoxaemia was not found in six patients admitted with only soft-tissue injuries. One or more subsequent attacks of subclinical hypoxaemia, each lasting a few days, occurred in half of those previously affected. Most episodes followed fracture operation or manipulation. Pulmonary thromboembolism seemed responsible in two patients, but it could be excluded in others given oral anticoagulant prophylaxis from soon after admission. Pulmonary fat embolism is the most likely explanation of the primary episodes and could account for most of the subsequent periods of hypoxaemia.

Hypoxaemia is a common feature of the clinical syndromes of fat embolism (Sproule, Brady and Gilbert 1964; Collins, Hudson, Hamacher, Rokous, Williams and Hardaway 1968; Wertzberger and Peltier 1968; Rokkanen, Landensuu, Kataha and Julkunen 1970; Ross 1970; Benoit, Hampson and Burgess 1972). Recent studies have also demonstrated early subclinical hypoxaemia in soldiers with wounded limbs (Collins, Gordon, Hudson, Irvin, Kelly and Hardaway 1968) and in civilian subjects with long bone fractures (Bradford, Foster and Nossel 1970; Rokkanen and colleagues 1970; Benoit and colleagues 1972; McCarthy, Mammen, Leblanc and Wilson 1973). The present study was designed by the use of serial blood gas analyses to throw further light on hypoxaemia after fracture, including its time of onset, duration, severity and frequency, its relationship to clinical events and the possibility of recurrent episodes.

\section{PATIENTS AND METHODS}

Fifty patients admitted with fractures were studied. Those with significant head, chest or abdominal injury or with clinically apparent respiratory or cardiac disease, which might account for hypoxaemia, were excluded.

Arterial blood gas analyses $\left(\mathrm{PaCO}_{2}, \mathrm{PaO}_{2}\right.$ and $\left.\mathrm{pH}\right)$ during air breathing and usually from femoral samples, were carried out by Radiometer equipment kept in the admission department. The patient's consent for arterial puncture was obtained. Many of the $\mathrm{PaO}_{2}$ results were checked in the hospital biochemistry laboratory from duplicate samples and the greatest difference between any two duplicates was 4 millimetres of mercury. The first sample was collected as soon as practical after admission: in seventeen patients within an hour of injury (within thirty minutes in eight cases, and at two and a half minutes in one case); between one and four hours in nineteen patients; and between four and twelve hours in

INITIAL $\mathrm{PaO}_{2}$ VALUES

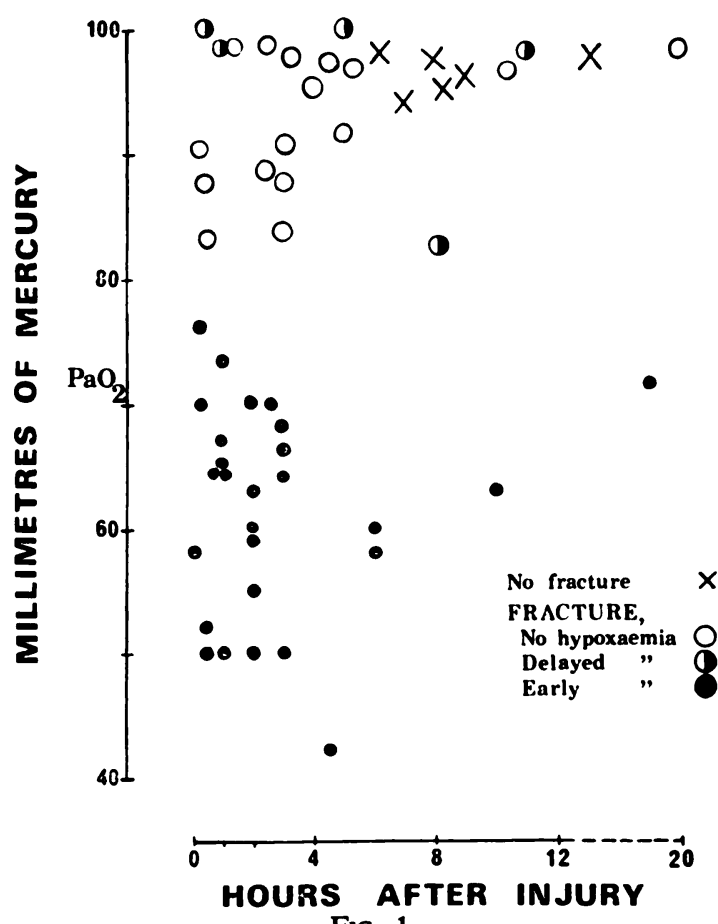

FIG. 1

$\mathrm{PO}_{2}$ values of first arterial samples after admission. Open circles are cases of fracture without primary hypoxaemia: solid circles, cases of fracture with primary hypoxaemia of rapid onset; and half open-half solid circles are cases of fracture with delayed primary hypoxaemia (see text) Crosses represent results in patients with soft-tissue trauma only.

S. S. Tachakra, M.B., B.S., F.R.C.S., M.S., Surgical Registrar, Birmingham Accident Hospital and Rehabilitation Centre, Bath Row, Birmingham 15, England.

S. Sevitt, M.Sc., F.R.C.Path., F.R.C.P.I., D.P.H., Consultant Pathologist, Birmingham Accident Hospital and Rehabilitation Centre, Bath Row, Birmingham 15, England. 
eleven patients (Fig. 1). The longest interval was twenty hours after injury. Further samples were taken at eighthourly intervals during the first twenty-four hours, twice a day during the next two days and then usually daily until the hypoxaemic episode was over. In patients who did not develop hypoxaemia, tests were terminated within a week. The same routine, often starting with eight-hourly samples, was followed after surgical operation, limb manipulation and traction-adjustment in those who had

TABLE I

Clinical Material

\begin{tabular}{|c|c|c|c|c|c|c|}
\hline & & & & & All patients & $\begin{array}{l}\text { Patients with } \\
\text { hypoxaemic } \\
\text { episodes }\end{array}$ \\
\hline Total patients & . & . & . & . & 50 & 32 \\
\hline (females) & . & . & . & . & (31) & (14) \\
\hline AGES (range) & . & . & . & . & $17-89$ years & \\
\hline Under 30 years & . & . & . & . & 5 & 5 \\
\hline $30-60$ years & . & . & . & . & 12 & 10 \\
\hline Over 60 years & . & . & . & . & 33 & 17 \\
\hline \multicolumn{7}{|l|}{ Fractures } \\
\hline \multicolumn{2}{|l|}{ Femur, subcapital } & . & . & . & 10 & 5 \\
\hline \multicolumn{3}{|c|}{ Femur, pertrochanteric } & . & . & 11 & 3 \\
\hline Femur, shaft & . & . & . & . & 11 & 9 \\
\hline Tibia . . & . & . & . & . & 9 & 7 \\
\hline Humerus . & . & . & . & . & 2 & 1 \\
\hline Pelvis . $\quad$. & . & . & . & . & 1 & 1 \\
\hline Femur and tibia & 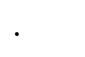 & . & . & . & 4 & 4 \\
\hline Femur, patella, $\mathrm{m}$ & naxilla & & . & . & 1 & 1 \\
\hline Pelvis and tibia & . & . & . & . & 1 & 1 \\
\hline \multicolumn{7}{|l|}{ ACCIDENTS } \\
\hline Road traffic. & . & . & $\cdot$ & . & 16 & 16 \\
\hline $\begin{array}{l}\text { (motor-cycle } \\
\text { pedestrians. } \\
\text { car occupants }\end{array}$ & . & $\cdot$ & . & $\begin{array}{l}7 \\
6 \\
3)\end{array}$ & & \\
\hline Domestic & . & . & . & . & 28 & 12 \\
\hline Industrial . & . & . & . & . & 6 & 4 \\
\hline
\end{tabular}

developed post-fracture hypoxaemia, and by this means subsequent episodes of hypoxaemia were found. The repeated arterial needling was without any complications. $\mathrm{PaO}_{2}$ values below 80 millimetres of mercury were considered to be below normal. Emphasis was laid on serial changes. As controls for the fracture patients, arterial blood gas analyses were also carried out in six patients with soft-tissue injuries of the limbs without fracture several hours after arrival in hospital. The levels were always found to be normal (94 to 98 millimetres of mercury) (Fig. 1).
Essential details of the fifty patients are given in Table I. Ages ranged from seventeen to eighty-nine years. There were thirty-one females and nineteen males. Fractures of a lower limb predominated. The twenty-eight patients injured in domestic accidents included twentyone with fractures of the hip (subcapital ten, pertrochanteric eleven) and accounted for the disproportionate number of females and elderly subjects (thirty-three over sixty years). The twenty-two patients admitted after road traffic accidents (sixteen patients) and industrial accidents (six patients) include all but one of the seventeen patients under sixty years of age. These accidents account for most of those with fractures confined to one femoral shaft or tibia, for those with fractures of a femur and tibia and for the single patients with fractures of the pelvis, pelvis and tibia, and femur, patella and maxilla.

Twenty-eight patients were given prophylactic courses of oral anticoagulant therapy with Warfarin, beginning on the day of injury or on the next day in accordance with established hospital policy (Sevitt and Gallagher 1959; Sevitt 1968). This included all those over forty years of age admitted with lower limb fractures. Drug dosage was controlled by repeated plasma prothrombin-time estimations often supplemented by partial-thromboplastin time tests (kaolin-cephalin time). The aim was to reduce prothrombin-time activity to between 24 and 18 per cent of the normal based on saline dilution curves of plasma, the levels required to inhibit venous thrombogenesis with minimum frequency of haemorrhage (Sevitt and Innes 1964). The prophylaxis was of value in eliminating pulmonary thromboembolism as a potential cause of the hypoxaemic episodes during the second or subsequent weeks after injury (see below).

Various clinico-pathological and radiological examinations were carried out as required. Surgical procedures, anaesthesia and limb manipulations were performed as indicated clinically. All patients survived.

\section{RESULTS}

One or more episodes of hypoxaemia developed in thirtytwo patients (64 per cent). They are divided into primary hypoxaemia and subsequent episodes.

Primary hypoxaemia-Twenty-seven of the thirty-two patients were already hypoxaemic at the first test after admission (Fig. 1). Typically the arterial $\mathrm{PO}_{2}$ fell to about 60 or 70 millimetres of mercury, remained at this level for a few days and then returned to normal within twentyfour hours (Fig. 2). $\quad \mathrm{PCO}_{2}$ estimates were not raised and in fourteen patients the values fell to between 25 and 35 millimetres of mercury during part of the hypoxaemic episode, indicating a degree of hyperventilation. In the great majority of patients the hypoxaemia was subclinical and neither cyanosis nor dyspnoea was present. The onset was rapid. Indeed, in a patient who sustained a fractured shaft of femur in a motor-cycle accident outside the hospital the first arterial sample, collected only two 
and a half minutes after injury, showed the $\mathrm{PaO}_{2}$ level to be already considerably lowered (58 millimetres of mercury) without clinical effects.

In five of the thirty-two patients one or more of the initial $\mathrm{PaO}_{2}$ values were normal (Figs. 1, 3 and 4) and

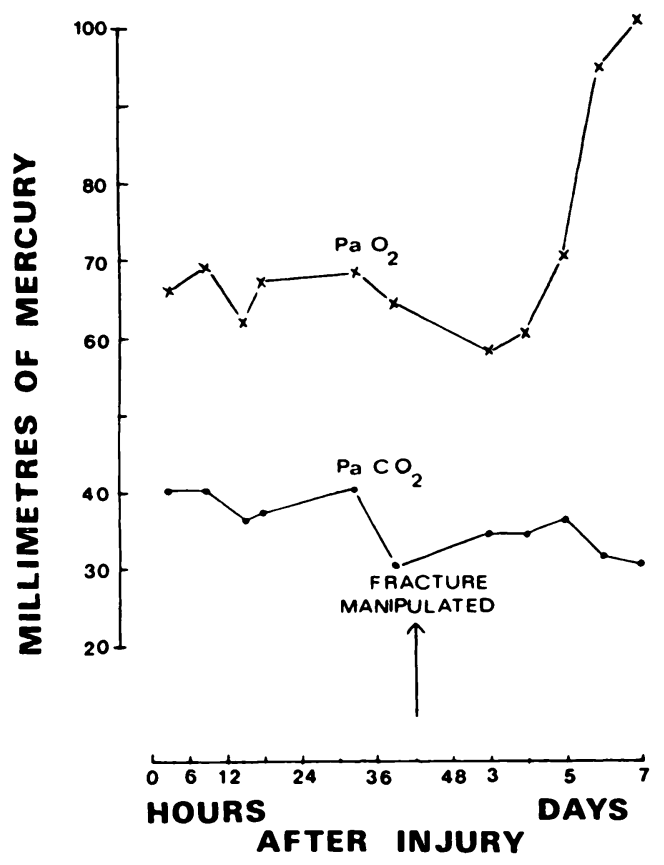

Fig. 2

Episode of primary hypoxaemia after fracture of tibia.

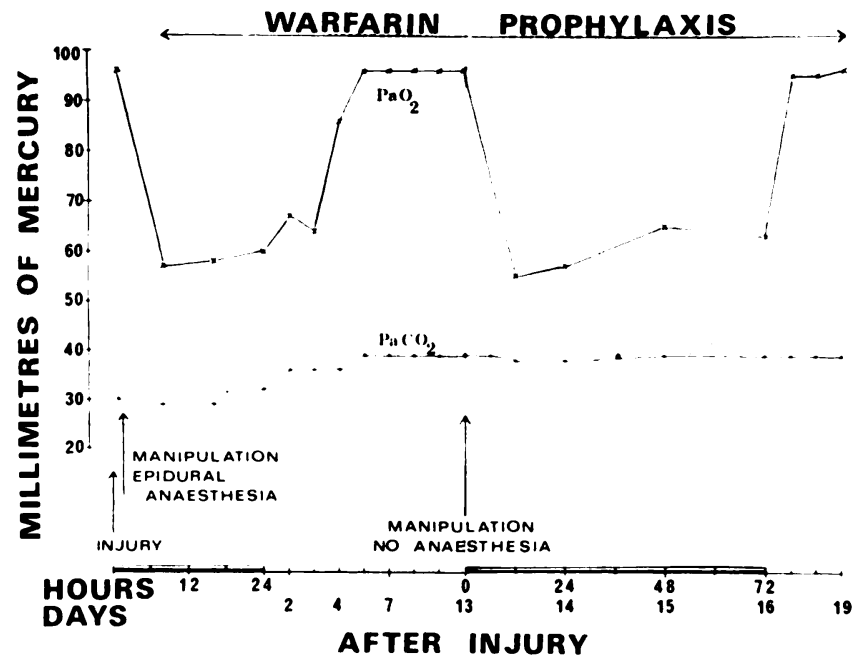

FIG. 3

Episode of primary hypoxaenia slightly delayed in onset after fracture of shaft of femur. A second attack began thirteen days after injury, after manipulation of the fracture. Note the Warfarin prophylaxis against thromboembolism.

the lowered values were first found between five hours and two days after injury. This may be termed delayed primary hypoxaemia. Four of these patients had recently undergone operations for fracture (Fig. 4), which brings the delayed primary episodes into line with second and third attacks apparently precipitated by operation or manipulation (see below).

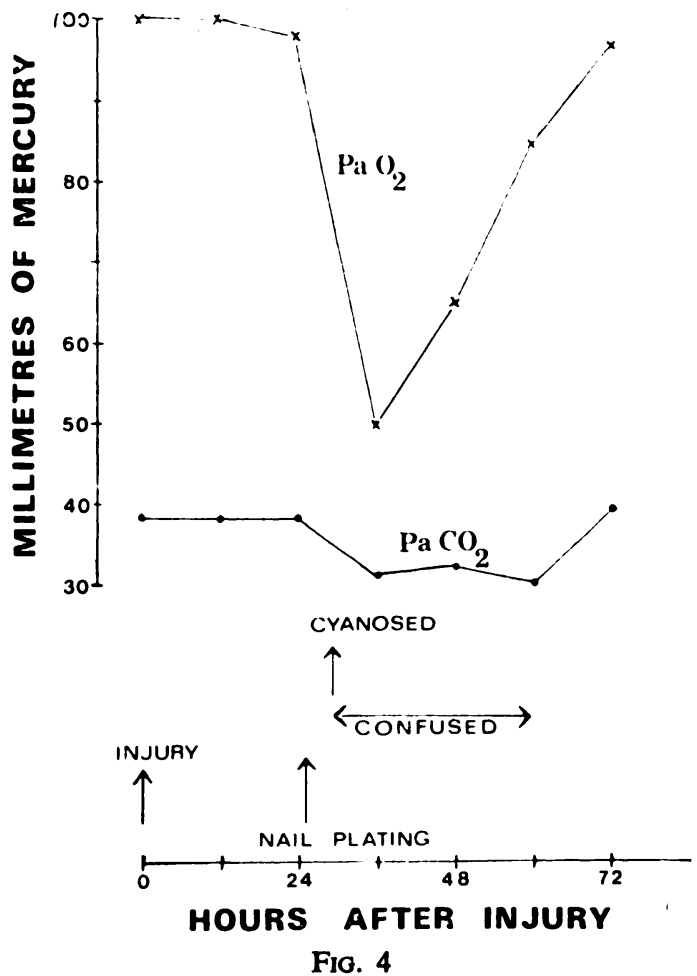

Primary hypoxaemia apparently precipitated by nail plating of the fractured femur, and associated with mild symptoms of fat embolism.

\section{PRIMARY HYPOXAEMIC EPISODES}

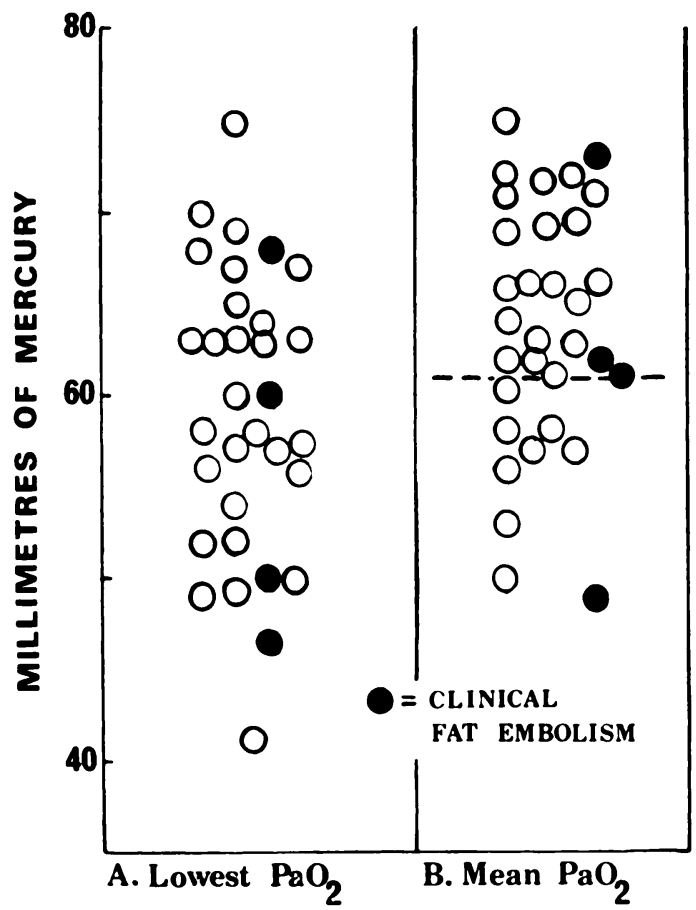

FIG. 5

Lowest (A) and mean (B) arterial $\mathrm{PO}_{2}$ values during primary hypoxaemic episodes. Solid black circles represent cases of clinical fat embolism. Interrupted line in $B$ is the mean of the thirty-two mean values. 
The means of the arterial $\mathrm{PO}_{2}$ estimates during the episodes of primary hypoxaemia are shown in Figure 5 (B). The individual means ranged from 49 to 75 millimetres of mercury with an average for all means of 61 millimetres of mercury. Mean values were between 71 and 80 millimetres in seven patients, 61 to 70 millimetres in seventeen, 51 to 60 in six, and at or just below 50 millimetres of mercury in two patients.

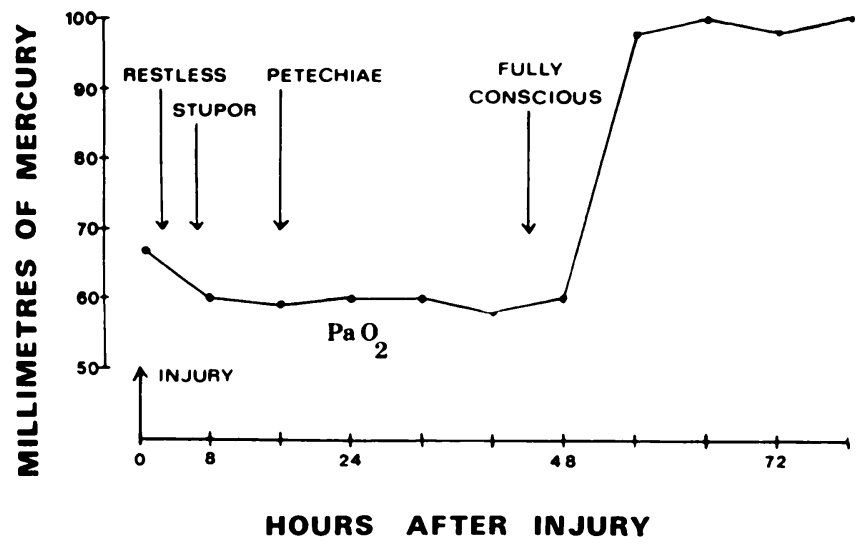

FIG. 6

Primary hypoxaemic episode after fracture of pelvis associated with mild symptoms of fat embolism.

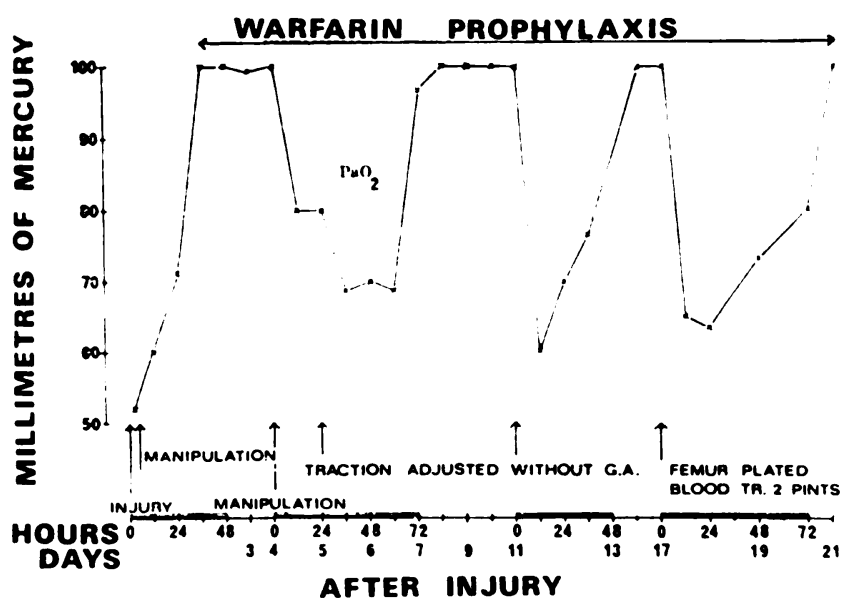

Fig. 7

Primary hypoxaemia after fracture of femur. Also three subsequent attacks, each apparently precipitated by manipulative or surgical intervention. Note the continued Warfarin prophylaxis against thromboembolism.

The lowest $\mathrm{PaO}_{2}$ values found in individual cases ranged from 41 to 75 millimetres of mercury (Fig. 5 (A)). They were between 41 and 50 millimetres in six patients, 51 to 60 millimetres in twelve and 61 to 70 in thirteen.

Recovery from hypoxaemia was quite rapid, sometimes taking place within twenty-four hours, and within twelve hours in those undergoing twice-daily sampling at the time. In twenty of the thirty-two patients the hypoxaemic episode lasted between two and five days.
The mean duration was five days, the periods ranging from one and a half days to three weeks. Hypoxaemia lasted between one and a half and two days in four patients, two to three days in ten, three to five days in ten, five to seven days in four, and longer than seven days in four patients. The prolonged periods may have been due to the onset of a second episode before the first had ended, or failure to discriminate between the first and subsequent attacks.

The frequency of primary hypoxaemia varied in different subgroups (Table I). It was very high in those with fractures of the shaft of the femur (nine out of eleven patients) or tibia (seven out of nine) and occurred in all those with fractures of two bones. On the other hand, the incidence was significantly lower in those with femoral

TABLE II

Second and Subsequent Hypoxaemic Episodes

\begin{tabular}{|c|c|c|c|c|c|}
\hline \multicolumn{3}{|l|}{ Site of fracture } & $\begin{array}{l}\text { Total } \\
\text { number of } \\
\text { patients }\end{array}$ & $\begin{array}{l}\text { Second } \\
\text { hypoxaemic } \\
\text { episode }\end{array}$ & $\begin{array}{l}\text { Third } \\
\text { hypoxaemic } \\
\text { episode }\end{array}$ \\
\hline Shaft of femur & . & . & 11 & 6 & 5 \\
\hline Tibia & . & . & 9 & 2 & 1 \\
\hline Subcapital femur & . & . & 10 & 0 & 0 \\
\hline Pertrochanteric fe & mur & . & 11 & 3 & 1 \\
\hline Humerus & . & . & 2 & 0 & 0 \\
\hline Pelvis . & . & . & 1 & 0 & 0 \\
\hline Femur and tibia & . & . & 4 & 3 & 1 \\
\hline Femur, patella and & maxill & & 1 & 1 & 1 \\
\hline Pelvis and tibia & . & . & 1 & 1 & 1 \\
\hline
\end{tabular}

pertrochanteric (three out of eleven patients) or subcapital fractures (five out of ten). The relatively low incidence in patients with hip fractures explains the relative infrequency in females (fourteen out of thirty-one), in elderly patients (seventeen out of thirty-three patients over sixty) and after domestic accidents (twelve out of twentyeight) since these factors are linked. On the other hand the more severe injury from road traffic accidents probably accounts for the 100 per cent frequency of hypoxaemia in that group, for the very high incidence in males (eighteen out of nineteen) and in patients under sixty years old (fifteen out of seventeen).

Clinical fat embolism - Four of the patients with primary hypoxaemia developed coincidental clinical evidence of fat embolism (Figs. 4 and 6). This represents 8 per cent of the series and 12.5 per cent of those with primary hypoxaemia. They recovered fully without treatment. Diagnosis was based on mild cerebral symptoms (stupor or confusion or both) in each case, mild respiratory effects (tachypnoea or cyanosis) in three and skin petechiae of characteristic distribution in all. Two episodes coincided with early primary hypoxaemia (Fig. 6), whereas the 
other two were examples of delayed primary hypoxaemia after nail-plating of subtrochanteric (Fig. 4) and comminuted transcervical fractures of the femur. The lowest arterial $\mathrm{PO}_{2}$ values were 47 and 50 millimetres of mercury in two cases, accounting for two of the six values at or below 50 millimetres of mercury (Fig. 1). In the other two patients, one with a fractured pelvis (Fig. 6) and the other with the comminuted hip fracture, the lowest $\mathrm{PaO}_{2}$ results were 60 and 68 millimetres of mercury. Respiratory symptoms were not observed in the latter case and were slight in the former one.

Subsequent hypoxaemic episodes-Further periods of subclinical hypoxaemia were found among half of the thirtytwo patients who developed primary episodes, beginning shorter lasting: one and a half to two days in ten patients, two to three days in four patients and for five days in two patients. Recovery from the second episode was as rapid as from the first. The $\mathrm{PCO}_{2}$ values were normal except in four patients in whom it fell to between 29 and 35 millimetres of mercury during the episode. Only three of the sixteen patients developed respiratory symptoms, which in two cases were attributed to post-operative chest infection.

Third attacks occurred in nine patients after the second had subsided. They began between ten and fifteen days after injury in four patients and during the third week in five subjects. The mean duration was four days and the episodes resembled the first and second attacks

TABLE III

InCidence of Hypoxaemia after Operation on or Manipulation of Fracture in ThirTy-two Patients Who had Primary Hypoxaemia

\begin{tabular}{|c|c|c|c|c|}
\hline Operation or manipulation & Preced & $\begin{array}{c}\text { ng } \mathrm{PO}_{2} \text { normal } \\
\begin{array}{c}\text { Number } \\
\text { with new } \\
\text { hypoxaemic } \\
\text { episode }\end{array}\end{array}$ & $\begin{array}{r}\text { Preced } \\
\text { than } 8 \\
\text { of } \\
\text { Total }\end{array}$ & $\begin{array}{l}\text { ing } \mathrm{PO}_{2} \text { less } \\
\text { millimetres } \\
\text { mercury } \\
\text { Number with } \\
\text { worsening of } \\
\text { hypoxaemia }\end{array}$ \\
\hline Nail-plating of fractured hips & 10 & 2 & 4 & 1 \\
\hline Tibial plating . & 1 & 1 & & \\
\hline Intramedullary nailing of fractured femurs & 2 & 2 & & \\
\hline All fracture-manipulations . & 21 & 9 & 17 & 12 \\
\hline Manipulations under general anaesthesia & 10 & 2 & 14 & 10 \\
\hline Manipulations without anaesthesia & 10 & 6 & 3 & 2 \\
\hline Manipulations with epidural anaesthesia & 1 & 1 & & \\
\hline All surgical interventions & 34 & 14 & 21 & 13 \\
\hline
\end{tabular}

after the latter had subsided. Sixteen had second attacks (Fig. 3) and nine had third attacks. One patient, a fit forty-nine-year-old man with a compound fracture of the femoral shaft suffered four clearly-defined episodes, each of the last three after some surgical procedure (Fig. 7).

Second episodes occurred in six of the eleven patients with fractures of the femoral shaft, in two out of nine with fractured tibias, in three of the eleven with pertrochanteric fractures and in three of the four with fractures of the femur and tibia (Table II). They began between five and ten days after the original injury in eight patients, between ten and fifteen days later in seven patients and on the eighteenth day in one case. The $\mathrm{PaO}_{2}$ values were normal between the end of the first and beginning of the second episode and the intervening periods were two or three days in six patients, four or six days in four subjects and seven or ten days in six patients. The hypoxaemia was similar in degree to the primary episode, the lowest values between 60 and 70 millimetres of mercury in seven patients and 50 to 60 millimetres of mercury in nine. However, it was generally in their degrees of intensity. No definite examples of clinical fat embolism were encountered during subsequent hypoxaemic episodes though retrospective analysis indicates that one or two mild attacks may have occurred.

Relationship to fracture-manipulation and operation-In many cases there was a clear post-hoc relationship between second and subsequent hypoxaemic attacks and fracture manipulation or operation. In twelve patients, second episodes had been preceded by open operation or closed manipulation of the fracture, including nail-plating of hip fractures (two patients), intramedullary nailing of a femoral shaft fracture (one patient) and fracturemanipulation (nine patients). The latter had been carried out without anaesthesia in three patients. Similar surgical interventions had preceded the third hypoxaemic attacks in six patients.

The incidence of new hypoxaemic episodes after operation and manipulation is shown in Table III. The table also shows the frequency of worsening of current hypoxaemia after these interventions. Altogether fiftyfive surgical operations or fracture-manipulations had 
been carried out, twenty-seven of which were followed either by new hypoxaemic attacks or a worsening of existing episodes. New hypoxaemic attacks after five of the thirteen fracture-operations included both intramedullary femoral nailings and two out of ten nailplatings of fractured hips. Four of the latter operations were done during hypoxaemic episodes and the arterial $\mathrm{PO}_{2}$ was significantly lower after one of them. New hypoxaemic attacks followed nine of the twenty-one fracture-manipulations carried out when $\mathrm{PaO}_{2}$ values were normal, and a worsening of hypoxaemia occurred after twelve of the seventeen manipulations done during hypoxaemic episodes. General anaesthesia was not necessarily responsible since six out of ten patients had new attacks and two out of three suffered a worsening of hypoxaemia after manipulations without anaesthesia.

Thromboembolism, Warfarin prophylaxis and hypoxaemia-New hypoxaemic attacks could be attributed to pulmonary thromboembolism in two patients who were not given anticoagulant prophylaxis. In one patient, a man aged thirty-three years, the $\mathrm{PaO}_{2}$ fell to 64 millimetres of mercury on the eleventh day after a femoral shaft fracture and remained below normal for four to five days; a pleural friction-rub was heard over the right mid-zone and a chest radiograph showed opacity of the left lower lobe attributed to collapse. There was also clinical evidence of deep venous thrombosis in the right calf. The other patient, a woman of thirty-five years, developed hypoxaemia from the sixth to the tenth days after a fracture of the femur and tibia (lowest $\mathrm{PO}_{2}, 50$ millimetres of mercury) with clinical evidence suggesting pulmonary embolism.

Of the twenty-eight patients who received oral anticoagulants, fifteen ( 54 per cent) developed primary hypoxaemia compared with seventeen of the twenty-two subjects ( 77 per cent) who did not receive such prophylaxis. The lower frequency in the group receiving anticoagulants may be attributed to the fact that prophylaxis was given only to patients over forty years old, thus including those with fractured hips with a lower incidence of post-fracture hypoxaemia (Table I).

Nine of the sixteen patients ( 56 per cent) who developed second episodes of hypoxaemia were currently receiving prophylactic Warfarin therapy. The incidence of new attacks was rather higher among those (with primary hypoxaemia) who had received anticoagulants (nine out of fifteen subjects; 60 per cent) than among those not anticoagulated (seven out of seventeen subjects; 41 per cent). Whatever the explanation of the difference, pulmonary thromboembolism can be excluded as a cause of second and subsequent hypoxaemic episodes in those currently receiving anticoagulants and probably also in most of those not receiving anticoagulants.

\section{DISCUSSION}

Serial blood gas analyses in fifty fracture patients without head, chest or abdominal injury demonstrated early episodes of hypoxaemia in thirty-two (64 per cent), most of whom were already hypoxaemic on admission to hospital soon after the accident. The arterial $\mathrm{PO}_{2}$ commonly fell to between 60 and 70 millimetres of mercury, occasionally lower, and the episode generally lasted a few days, sometimes longer. Neither cyanosis nor dyspnoea was present in the great majority, and the hypoxaemia was not associated with $\mathrm{CO}_{2}$ retention. It was subclinical presumably because the arterial oxyhaemoglobin saturation was not much lowered at the levels of $\mathrm{PaO}_{2}$ found. The findings substantiate the early classical observation of Cournand, Riley, Bradley, Breed, Noble, Lauson, Gregersen and Richards (1943) that the range of oxy-haemoglobin saturation in the arterial blood of patients with fractures was lower than in those with uncomplicated haemorrhage, and confirm and extend the observations in recent reports on post-fracture hypoxaemia. Collins (1969) reported that the arterial $\mathbf{P O}_{2}$ fell below 80 millimetres of mercury in one-third of thirtythree subjects with comminuted femoral shaft fractures; Bradford, Foster and Nossel (1970) found arterial oxyhaemoglobin saturations below 90 per cent in eight out of twenty-three patients with one or more fractures of the tibia and femur; and McCarthy and colleagues (1973) observed a fall in $\mathrm{PaO}_{2}$ below 80 millimetres of mercury during the first two days after injury in twenty-eight out of fifty patients with "fractures of the extremity". In the present study the frequency was related to the origin, nature and severity of the fractures. Hypoxaemia developed in all sixteen patients with injuries sustained in road traffic accidents compared with 43 per cent of patients after domestic accidents, and in 80 per cent of twenty patients with fractures of the shaft of the femur or tibia compared with 38 per cent of twenty-one patients with fractures of the hip.

The time relations of hypoxaemia occurring soon after fracture are consistent with the rapidity with which fat emboli accumulate in the lung after fractures of marrow bones, and the time of their maximum appearance (Sevitt 1962). Pulmonary fat embolism is the likely cause. This is supported by the development of clinical features of fat embolism in a few cases and by the normal $\mathrm{PaO}_{2}$ values found in a group of subjects with soft-tissue injuries, without fractures. However, it cannot be assumed that fat embolism is entirely responsible for the hypoxaemia in all cases. Other causes like bed rest, severe venous hypoxaemia from shock (Freeman and Nunn 1963), post-traumatic pulmonary microthromboemboli (Eeles and Sevitt 1967) and general anaesthesia when given early, may contribute in varying degrees. However, clinical shock was not apparent in most of the present subjects, and the hypoxaemia often began before operation or anaesthesia was carried out. Blood transfusion during the first two days was required for only ten of the thirty-two patients with primary hypoxaemia $(0.5$ to 1.5 litres in nine patients).

If it is accepted that lung fat embolism is largely responsible for the primary episode, it remains to be 
explained why the embolism does not produce hypoxaemia in many other fracture cases. Variations in the degree of lung embolism, or equally important, variations in the amount of secondary alveolar haemorrhage and oedema, might account for the differences. In man, gross pulmonary fat embolism is generally associated with severe or multiple fractures (Emson 1958; Sevitt 1962) and the multiple small lesions found in the lungs would probably explain the onset of the moderate hypoxaemia now reported. However, it is doubtful whether they could account for the more severe hypoxaemia of some patients with clinical fat embolism (Sevitt 1973).

Serial follow-up studies in the thirty-two patients with primary hypoxaemia demonstrated second periods in sixteen, third episodes in nine of them and one patient had several attacks. In intensity these episodes resembled primary hypoxaemia, but they were generally shorter in duration, most lasting two to four days. The new episodes began days after the previous one had subsided and most of them clearly followed operative or manipulative intervention on the fractured limb. Similar interventions carried out during an episode of hypoxaemia often worsened the degree of hypoxaemia. General anaesthesia was not responsible, because eight of the thirteen manipulations carried out without anaesthesia were followed by new hypoxaemic episodes or an increase of current hypoxaemia. Pulmonary thrombo-embolism was or could have been responsible in two subjects, but it was most unlikely in eight patients currently receiving prophylactic courses of Warfarin against venous thrombogenesis. The conclusion cannot be avoided that most second or subsequent attacks of hypoxaemia were the result of fresh episodes of pulmonary fat embolism related to disturbance of the fracture site.

Two of the four cases of clinical fat embolism followed early operation on the fractures, which suggests that the timing increased the risk probably through adding to the number of emboli liberated. On the other hand, unequivocal clinical embolism was not associated with subsequent hypoxaemic episodes and this may have clinical significance relevant to the timing of fracture operations. Further experience on this aspect is needed and it is possible that arterial $\mathrm{PO}_{2}$ estimations may help to assess the time of least risk.

We are grateful to Mr R. Evans and Mr J. E. M. Smith, Consultant Surgeons, for access to their patients and for their helpful interest. Thanks are also due to Mr J. Lloyd, Chief Technician in the Biochemistry Department, for some of the biochemical results.

\section{REFERENCES}

Benoit, P. R., Hampson, L. G., and Burgess, J. H. (1972) Value of arterial hypoxemia in the diagnosis of pulmonary fat embolism. Annals of Surgery, 175, 128-137.

Bradford, D. S., Foster, R. R., and Nossel, H. L. (1970) Coagulation alterations, hypoxemia and fat embolism in fracture patients. Journal of Trauma, 10, 307-321.

Collins, J. A. (1969) The causes of progressive pulmonary insufficiency in surgical patients. Journal of Surgical Research, 9, 685-704.

Collins, J. A., Gordon, W. C., Jun., Hudson, T. L., Irvin, R. W., Jun., Kelly, T., and Hardaway, R. M., II (1968) Inapparent hypoxemia in casualties with wounded limbs. Annals of Surgery, 167, $511-520$.

Collins, J. A., Hudson, T. L., Hamacher, W. R., Rokous, J., Williams, G., and Hardaway, R. M., III (1968) Systemic fat embolism in four combat casualties. Annals of Surgery, 167, 493-499.

Cournand, A., Riley, R. L., Bradley, S. E., Breed, E. S., Noble, R. P., Lauson, A. D., Gregersen, M. I., and Richards, D. W. (1943) Studies of the circulation in clinical shock. Surgery, 13, 964-995.

Eeles, G. H., and Sevitt, S. (1967) Microthrombosis in injured and burned patients. Journal of Pathology and Bacteriology, 93, $275-293$.

Emson, H. E. (1958) Fat embolism studied in 100 patients dying after injury. Journal of Clinical Pathology, 11, 28-35.

Freeman, J., and Nunn, J. F. (1963) Ventilation-perfusion relationships after haemorrhage. Clinical Science, 24, $135-147$.

McCarthy, B., Mammen, E., LeBlanc, L. P., and Wilson, R. F. (1973) Subclinical fat embolism: a prospective study of 50 patients with extremity fractures. Journal of Trauma, 13, 9-16.

Rokkanen, P., Lahdensuu, M., Kataja, J., and Julkunen, H. (1970) The syndrome of fat embolism: analysis of thirty consecutive cases compared to trauma patients with similar injuries. Journal of Trauma, 10, 299-306.

Ross, A. P. J. (1970) The fat embolism syndrome: with special reference to the importance of hypoxia in the syndrome. Annals of the Royal College of Surgeons of England, 46, 159-171.

Sevitt, S. (1962) Fat Embolism. London: Butterworths.

Sevitt, S. (1968) Thromboembolism and its prevention. Proceedings of the Royal Society of Medicine, 61, 143-147.

Sevitt, S. (1973) The significance of fat embolism. British Journal of Hospital Medicine, 9, 784-793.

Sevitt, S., and Gallagher, N. G. (1959) Prevention of venous thrombosis and pulmonary embolism in injured patients. A trial of anticoagulant prophylaxis with phenindione in middle-aged and elderly patients with fractured necks of femur. Lancet, 2, 981-989.

Sevitt, S., and Innes, D. (1964) Prothrombin-time and thrombotest in injured patients on prophylactic anticoagulant therapy. Lancet, 1, 124-129.

Sproule, B. J., Brady, J. L., and Gilbert, J. A. L. (1964) Studies on the syndrome of fat embolization. Canadian Medical Association Journal, 90, 1243-1247.

Wertzberger, J. J., and Peltier, L. (1968) Fat embolism: the importance of arterial hypoxia. Surgery, 63, 626-629. 